\title{
Perspective of polymer-based solid-state Li-S batteries
}

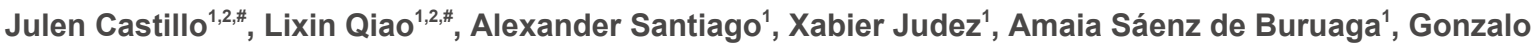 \\ Jiménez-Martín ${ }^{1,2}$, Michel Armand ${ }^{1}$, Heng Zhang ${ }^{3}$,*, Chunmei Li ${ }^{1, *}$ \\ ${ }^{1}$ Centre for Cooperative Research on Alternative Energies (CIC energiGUNE), Basque Research and Technology Alliance (BRTA), \\ Alava Technology Park, Vitoria-Gasteiz 01510, Spain. \\ ${ }^{2}$ Department of Chemical Engineering, University of the Basque Country (UPV/EHU), Barrio Sarriena, s/n, Leioa 48940, Spain. \\ ${ }^{3}$ Key Laboratory of Material Chemistry for Energy Conversion and Storage (Ministry of Education), School of Chemistry and \\ Chemical Engineering, Huazhong University of Science and Technology, Wuhan 430074, China. \\ ${ }^{\#}$ Authors contributed equally.
}

*Correspondence to: Dr. Chunmei Li, Centre for Cooperative Research on Alternative Energies (CIC energiGUNE), Basque Research and Technology Alliance (BRTA), Alava Technology Park, Albert Einstein 48, Vitoria-Gasteiz 01510, Spain. E-mail: cli@cicenergigune.com; Prof. Heng Zhang, Key Laboratory of Material Chemistry for Energy Conversion and Storage (Ministry of Education), School of Chemistry and Chemical Engineering, Huazhong University of Science and Technology, 1037 Luoyu Road, Wuhan 430074, China. E-mail:hengzhang2020@hust.edu.cn

How to cite this article: Castillo J, Qiao L, Santiago A, Judez X, Sáenz de Buruaga A, Jiménez-Martín G, Armand M, Zhang H, Li C. Perspective of polymer-based solid-state Li-S batteries. Energy Mater 2022;2:200003.

https://dx.doi.org/10.20517/energymater.2021.25

Received: 3 Dec 2021 First Decision: 28 Dec 2021 Revised: 16 Jan 2022 Accepted: 21 Jan 2022 Published: 11 Feb 2022

Academic Editor: Yuping Wu Copy Editor: Yue-Yue Zhang Production Editor: Yue-Yue Zhang

\begin{abstract}
Li-S batteries, as the most promising post Li-ion technology, have been intensively investigated for more than a decade. Although most previous studies have focused on liquid systems, solid electrolytes, particularly all-solidstate polymer electrolytes (ASSPEs) and quasi-solid-state polymer electrolyte (QSSPEs), are appealing for Li-S cells due to their excellent flexibility and mechanical stability. Such Li-S batteries not only provide significantly improved safety but are also expected to augment the all-inclusive energy density compared to liquid systems. Therefore, this perspective briefly summarizes the recent progress on polymer-based solid-state Li-S batteries, with a special focus on electrolytes, including ASSPEs and QSSPEs. Furthermore, future work is proposed based on the existing development and current challenges.
\end{abstract}

Keywords: Solid-state Li-S batteries, polymer electrolytes, quasi-solid-state polymer electrolyte, energy-density estimations 


\section{INTRODUCTION}

Rechargeable lithium-ion batteries have attracted prodigious attention as energy storage systems to power portable electronics and electronic vehicles, owing to their high cycle life and energy efficiencies ${ }^{[1-4]}$. However, future scenarios cannot be fully accomplished given the insufficient energy density of current Liion batteries (i.e., $\left.<350 \mathrm{Wh} \mathrm{kg}^{-1}\right)^{[5-7]}$ and thus the development of electrochemical storage technologies with enhanced energy density is crucially needed. Among all the post Li-ion technologies, lithium-sulfur (Li-S) batteries are considered to be the most auspicious and viable alternatives considering their extraordinary energy density (i.e., theoretical capacity of $2600 \mathrm{Wh} \mathrm{kg}^{-1}$ ), environmental friendliness and cost effectiveness $^{[8-10]}$.

Li-ion conducting electrolytes, as indispensable battery components, play a pivotal role in determining the performance of rechargeable Li-S batteries ${ }^{[11]}$. Commonly used liquid electrolytes (LEs) for Li-S batteries include lithium salts [e.g., lithium bis(trifluoromethanesulfonyl)imide (LiTFSI)] and organic ether solvents [e.g., 1,2-dimethoxyethane (DME) and 1,3-dioxolane (DOL) $]^{[12]}$. However, such LEs have intrinsic problems, including proneness to leakage and flammability, which may cause fire, explosion and other safety issues ${ }^{[13]}$. In addition, soluble polysulfide (PS) $\mathrm{Li}_{2} \mathrm{~S}_{n} 4 \leq n \leq 8$ intermediates can diffuse between the sulfur cathode and lithium metal $\left(\mathrm{Li}^{\circ}\right)$ anode during the charge/discharge processes (known as the PS "shuttle effect"), which leads to the irreversible loss of electroactive materials and deterioration of the electrode-electrolyte interphases, particularly for the $\mathrm{Li}^{\circ}$ anode, thus significantly shortening the cycle life of the cell ${ }^{[12,14]}$. Due to their negligible volatility, appealing flexibility and mechanical stability, polymer electrolytes (PEs) ${ }^{[15,16]}$, including all-solid-state polymer electrolytes (ASSPEs) ${ }^{[17]}$ and quasi-solid-state polymer electrolytes (QSSPEs) ${ }^{[18,19]}$, not only significantly improve battery safety, but are also expected to augment the all-inclusive energy density compared to liquid systems ${ }^{[14]}$.

Considering the aforementioned points and the intrinsic advantages of PE-based Li-S batteries, herein we present an overview of the recent progress and advancement in PE-based (ASSPEs and QSSPEs) Li-S batteries and a systematic analysis of the projected energy density of Li-S batteries based on different electrolytes. Furthermore, this perspective also includes the remaining challenges that need to be solved for the practical applications and future prospects of PE-based Li-S battery technologies.

\section{ALL-SOLID-STATE POLYMER ELECTROLYTES}

Generally, ASSPEs composed of lithium salts, polymer matrices and/or solid additives have been considered as some of the most appealing candidates to replace LEs due to their high safety, excellent flexibility and processability, and superior physical contact with the electrodes, in contrast to inorganic-based solid electrolytes ${ }^{[20]}$. Among all the different polymer matrices, poly(ethylene oxide) (PEO) is the most prevailing choice for developing ASSPE-based Li-S batteries, owing to its superior solvation ability, excellent mechanical properties, low cost and facile processability ${ }^{[2-25]}$. In PEO-based ASSPEs, lithium salts are dissociated and solvated by Lewis-base ether units (i.e., ethylene oxide) and the transportation of lithium cations is associated with the segmental motion of PEO chains by intrachain and/or interchain hopping ${ }^{[26]}$. It is widely acknowledged that lithium salts play a decisive role in decreasing the glass transition temperature $\left(T_{\mathrm{g}}\right)$, facilitating the segmental motion and increasing the ionic conductivity of ASSPEs ${ }^{[27]}$. More importantly, the nature of the salt anions determines the properties and qualities of the solid electrolyte interphase (SEI) and cathode electrolyte interface (CEI) layers formed on the electrodes, as well as the flexibility and wettability of the electrolytes ${ }^{[28]}$. 
LiTFSI was firstly employed as a conducting salt in ASSPEs by Armand et al. ${ }^{[29,30]}$ in 1986 and has since become the most widely used lithium salt in recent decades because of its excellent chemical stability and anionic flexibility generated from the delocalized negative charge over flexible S-N-S bonds. However, LiTFSI/PEO-based ASSPEs provide inferior SEI formation in contact with the $\mathrm{Li}^{\circ}$ anode due to the unfavorable anion chemistry. Furthermore, PS can still be dissolved in PEO at high temperatures (i.e., $70{ }^{\circ} \mathrm{C}$ ), resulting in infinite charging (PS shuttle) already in the first cycles and notorious lithium dendrite growth $^{[28,31]}$. The same phenomenon and cell performance are also observed in Li-S cells with lithium trifluoromethanesulfonate (LiTf)/PEO-based ASSPEs ${ }^{[32,33]}$. The cycling performance of PEO-based Li-S cells was improved for the first time by Ma et al. ${ }^{[34]}$, where LiTFSI was replaced by an asymmetric imide salt, lithium (trifluoromethanesulfonyl)( $n$-nonafluorobutanesulfonyl) imide. This improvement was ascribed to the participation of the $-\mathrm{C}_{4} \mathrm{~F}_{9}$ group in forming stable interphases with the electrodes.

In another work, Judez et al. ${ }^{[35]}$ demonstrated a significant improvement in PEO-based Li-S cells when replacing LiTFSI with another imide salt, lithium bis(fluorosulfonyl)imide (LiFSI). A remarkably high Coulombic efficiency (CE) and prolonged cycle life were achieved and ascribed to the formation of a LiFrich SEI layer on the $\mathrm{Li}^{\circ}$ anode. However, the Li-S cell with LiFSI/PEO-based ASSPEs presented a lower capacity compared to the LiTFSI-based cell [e.g., $<800 \mathrm{mAh}_{\text {sulfur }}{ }^{-1}$ (LiFSI) vs. $>900 \mathrm{mAh} \mathrm{g}_{\text {sulfur }}{ }^{-1}$ (LiTFSI)] because of the poorer wetting properties of the $-\mathrm{SO}_{2} \mathrm{~F} v \mathcal{~ s} .-\mathrm{SO}_{2} \mathrm{CF}_{3}$ groups ${ }^{[28,35]}$. In a subsequent study, another imide salt with an asymmetric structure, lithium (fluorosulfonyl)(trifluoromethanesulfonyl)imide (LiFTFSI), consisting of both the $-\mathrm{SO}_{2} \mathrm{~F}$ and $-\mathrm{SO}_{2} \mathrm{CF}_{3}$ moieties, was proposed by Eshetu et al. ${ }^{[28]}$ with the aim of combining the merits of both the FSI $^{-}$and TFSI $^{-}$anions. It was anticipated that the electrochemical decomposition of the FTFSI ${ }^{-}$anion could form a synergistic SEI layer with well-balanced organic and inorganic species [Figure 1A]. Effectively, such cells delivered a high specific capacity (1394 $\mathrm{mAh}_{\mathrm{sulfur}^{-1}}{ }^{-1}$ and areal capacity $\left(1.2 \mathrm{mAh} \mathrm{cm}^{-2}\right)$, excellent CE (nearly 100\%) and prominent rate capabilities $\left(\sim 500 \mathrm{mAh} \mathrm{g}_{\text {sulfur }}^{-1}\right.$ at $0.5 \mathrm{C}$ ). All these results emphasize that a chemically and mechanically stable SEI layer is prominent for the cycle life and rate performance of ASSPE-based Li-S batteries ${ }^{[36-38]}$.

To further alleviate the lithium dendrite growth and inhibit the "shuttle effect" of aggressive PS, the same group reported a novel designer anion, (difluoromethanesulfonyl) (trifluoromethanesulfonyl)imide $(\mathrm{DFTFSI})^{[38]}$. This anion is capable of simultaneously facilitating $\mathrm{Li}$ cation transport $\left(\mathrm{T}_{\mathrm{Li}}{ }^{+}\right)$and improving the interfacial compatibility towards the $\mathrm{Li}^{\circ}$ electrode, thereby enhancing the Li-S cell performance ${ }^{[39]}$. It was demonstrated that hydrogen bonding could be formed between the $\mathrm{H}$ atoms of the newly introduced $-\mathrm{CF}_{2} \mathrm{H}$ functional group and the $\mathrm{O}$ atoms of $\mathrm{PEO}$, to diminish the anion mobility and enhance $\mathrm{T}_{\mathrm{Li}}{ }^{+}$. In particular, the $-\mathrm{CF}_{2} \mathrm{H}$ moiety in the DFTFSI is electrochemically labile, which is facilely decomposed to form ionically conductive $\mathrm{LiH}$ and mechanically stable $\mathrm{LiF}$ species as a SEI layer on the $\mathrm{Li}^{\circ}$ anode, thereby ensuring excellent interfacial properties [Figure 1B]. Meanwhile, DFTFSI- also shows a superior chemical stability towards the aggressive PS species, as revealed by density functional theory calculations. All these aspects guarantee an ultrahigh cycle life (more than 1300 cycles) with CEs close to 100\% [Figure 1C], albeit with a decline in capacity.

In addition to fluorine-containing imide salts, non-fluorinated salt anions have also attracted significant attention. In this respect, lithium tricyanomethanide (LiTCM), a cost-effective and low toxicity fluorine-free salt was proposed and employed as the main salt or additive in PEO-based ASSPEs for Li-S batteries, demonstrating the unique interfacial properties and high CE of the cell ${ }^{[38,40]}$. As shown in Figure 1D, unlike the lithium deposits of the fluorine-containing LiTFSI, the LiTCM-based electrolyte shows more uniform and compact deposits with a bluish black color, owing to the formation of highly conducting $\mathrm{Li}_{3} \mathrm{~N}$ and carbon-containing species (e.g., polymeric $\mathrm{C}=\mathrm{N}$ network), which are generated from the reduction of the 
A

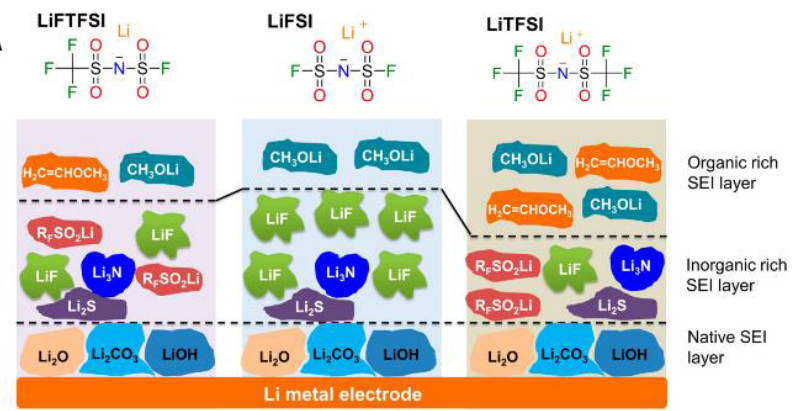

B

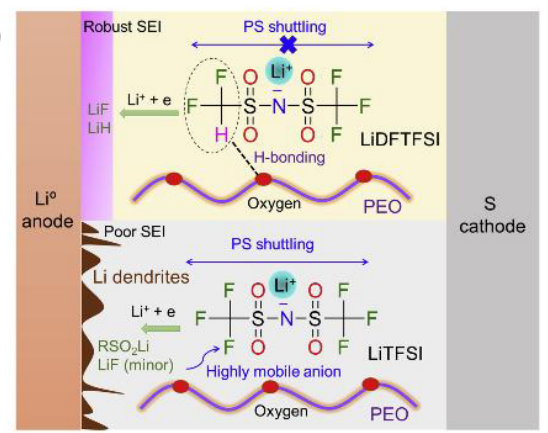

D
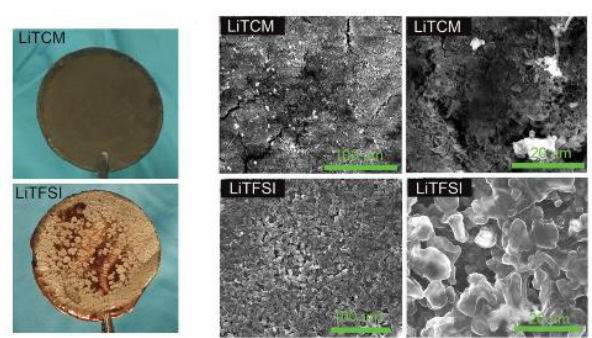

$\mathbf{F}$

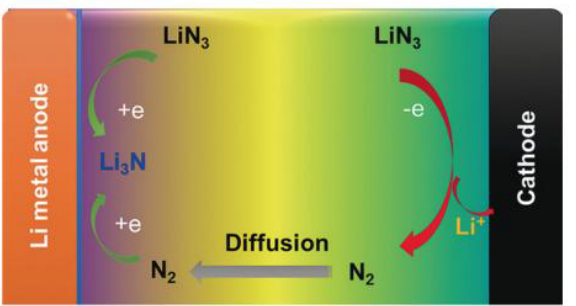

Figure 1. (A) Schematic illustration of the solid electrolyte interphase layer formed on a Li anode in electrolytes with different lithium salts. Reproduced from Ref. ${ }^{[28]}$ with permission. Copyright 2018 American Chemical Society. (B) Role of the two salts in SPE-based Li-S batteries. (C) Long-term cycling stability of Li-S cells based on the LiDFTFSI/PEO electrolyte (0.1/0.1 C, after C-rate test, *erratic Coulombic efficiency at around 400th cycle). Figure $1 B$ and $C$ reproduced from Ref. ${ }^{[39]}$ with permission. Copyright 2019 Cell Press. Optical and scanning electron microscopy images (D) and X-ray photoelectron spectroscopy spectra (E) of lithium deposited onto Cu substrates in LiX/DME (X = TCM or TFSI) LEs. Reproduced from Ref. ${ }^{[40]}$ with permission. Copyright 2019 Wiley-VCH. (F) Schematic illustration of electrochemical reactions of $\mathrm{LiN}_{3}$ in lithium-metal batteries. Reproduced from Ref. ${ }^{[43]}$ with permission. Copyright 2017 Wiley-VCH.

$\mathrm{TCM}^{-}$anion, as suggested by the X-ray photoelectron spectra in Figure 1E.

However, the practical application of the aforementioned emerging salts is still hindered by multi-step, time-consuming and laborious syntheses or the currently small production scale, resulting in high costs. It is accepted that the employment of electrolyte additives is a feasible, economical and facile strategy (small doses for large effects) to meet the requirements for achieving an ideal SEI layer and long-term cyclability ${ }^{[41,42]}$. As an additional step to the use of the above listed salts (LiFSI, LiFTFSI, LiDFTFSI and LiTCM) as additives into LiTFSI/PEO ASSPEs, lithium azide $\left(\mathrm{LiN}_{3}\right)$ has been proposed as a novel additive that can be reduced into $\mathrm{Li}_{3} \mathrm{~N}$ species to form a highly conductive SEI layer. Simultaneously, $\mathrm{LiN}_{3}$ can also be oxidized on the cathode to form molecular nitrogen $\left(\mathrm{N}_{2}\right)$, which can then migrate to the $\mathrm{Li}^{\circ}$ side and become further reduced into $\mathrm{Li}_{3} \mathrm{~N}$ to reinforce the ion conduction of the SEI layer [Figure $1 \mathrm{~F}$ ], resulting in a 
Li-S cell with a high reversible capacity of $\sim 800 \mathrm{mAh} \mathrm{g}^{-1}$, even after 30 cycles $^{[43]}$.

Tuning the anion chemistry in ASSPEs to achieve robust SEIs on $\mathrm{Li}^{\circ}$ in order to improve the cycle life of $\mathrm{Li}-\mathrm{S}$ cells is one of the approaches utilized in the literature. Another effective approach is to optimize the cathode, with the aim of confining PS species within the cathode matrix to further suppress the shuttle effect and avoid poisoning of the $\mathrm{Li}^{\circ}$ and active material loss upon cycling. The work of Gao et al. ${ }^{[4]}$ demonstrated a nanoscale encapsulation concept based on $\mathrm{Li}_{2} \mathrm{~S} @ \mathrm{TiS}_{2}$ core-shell particles, which was originally developed for liquid systems, to also be effective in ASSPEs, with $>400 \mathrm{mAh} \mathrm{g}^{-1}$ reached after 150 cycles. Not limited to the physical confinement of PS, organosulfur-type active materials have been used to replace elemental S as an example of the chemical confinement of PS. An improved cycle life of a Li-S cell has been illustrated, even with a poor SEI formation ability electrolyte (LiTFSI/PEO), using a cathode composed of a Scontaining copolymer (prepared via the inverse vulcanization of sulfur with divinylbenzene) ${ }^{[45]}$.

It is generally accepted that sulfur cathodes have an intrinsic drawback in that elemental sulfur possesses inferior electronic and ionic conductivity, resulting in sluggish reaction kinetics of the cathodes ${ }^{[46-48]}$. Unfortunately, this issue is amplified in ASSPE-based Li-S cells due to the poor wettability and compatibility of the ASSPE toward the sulfur electrode. Therefore, the incorporation of extra electronic/ionic conductors into the cathode materials for ASSPE-based Li-S cells is highly needed. Previous studies have demonstrated that carbon materials [e.g., acetylene black $(\mathrm{AB})^{[49,50]}$, Ketjenblack $(\mathrm{KB})^{[51]}$, graphene oxide $(\mathrm{GO})^{[52,53]}$ and graphene-carbon nanotubes $\left.{ }^{[54]}\right]$ and $\mathrm{Li}^{+}$conductive polymers [e.g., polyethylene glycol (PEG)] are the most effective and appealing candidates for use in Li-S cells to enhance the electronic/ionic conductivities of sulfur cathodes. For example, a composite cathode with PEG-grafted graphene oxide (GO) was reported by Zhang et al. ${ }^{[52]}$, serving as a Li-ion conductor, with the grafted PEG in direct contact with the electron conductor (i.e., GO), which greatly enhanced the Li-ion transport efficiency. In addition, cathode preparation methods, e.g., gas-phase mixing, ball-milling and liquid deposition methods, also have a significant impact on improving the ionic conductivity of cathodes ${ }^{[48]}$. Zhou et al. ${ }^{[55]}$ prepared a well-dispersed S@KB composite via a solution deposition of sulfur onto KB directly. Compared to the simply mixed S/KB composite, the prepared S@KB composite showed better sulfur/carbon contact, a smaller (nano) sulfur particle size and a more homogeneous distribution, resulting in a high capacity and $\mathrm{CE}$, as well as fast kinetics.

\section{QUASI-SOLID-STATE LI-S CELLS}

As discussed above, ASSPEs suffer from low ionic conductivity and poor contact with electrodes at room temperature, which hinder their application as electrolytes for high-performance Li-S batteries from a practical perspective. One of the most feasible approaches to alleviate the above dilemma of ASSPEs is the use of QSSPEs, which are also known as gel polymer electrolytes (GPEs). These electrolytes are based on the incorporation of an organic liquid compound, known as a plasticizer, into a solid polymer matrix. The improvement in ionic conductivity originates from the enhanced segmental mobility of polymer backbones in the presence of plasticizing agents, thus offering rapid ionic transport. The significant research efforts carried out in recent years have led to substantial scientific progress in improving the performance of QSSPE-based Li-S cells, such as their mechanical properties ${ }^{[56]}$, Li-ion transference number ${ }^{[57,58]}$ and/or thermal stability [Table 1] $]^{[59]}$.

Conventionally, ex-situ methods (generally physical methods), like solvent-casting, phase inversion and electrospinning, have been used to prepare QSSPEs for Li-S cells. However, one of the main issues is the weak interactions between the electrolyte components, which is inherent for QSSPEs prepared by such methods. This can lead to oozing of the liquid plasticizer, which induces a deterioration in both 
Table 1. State-of-the-art in QSSPE-based Li-S batteries

\begin{tabular}{|c|c|c|c|c|c|c|c|c|}
\hline Entry & Electrolyte components & $\sigma^{[\mathrm{a}]} / \mathrm{mS} \mathrm{cm}^{-1}$ & $T_{\mathrm{Li}}+^{[\mathrm{b}]}$ & $C_{i}^{[c]} / \mathrm{mAh} \mathrm{g}^{-1}$ & $C_{e}^{[d]} / m^{\prime} A h g^{-1}$ (cycle life) & $\mathrm{SL}^{[\mathrm{e}]} / \mathrm{mg} \mathrm{cm}^{-2}$ & C-rate & Ref. \\
\hline 1 & PETEA + 1.0 M LiTFSI in DOL/DME + 1 wt. \% LiNO $_{3}$ & $11.3\left(25^{\circ} \mathrm{C}\right)$ & 0.47 & 647 & 530 (400th cycle) & $1.2-1.5$ & $0.5 \mathrm{C}$ & {$[60]$} \\
\hline 2 & PEO/LAGP + 1.0 M LiTFSI in TEGDME & 1.15 & 0.28 & 725 & 700 (300th cycle) & 1.0 & $0.5 \mathrm{C}$ & [61] \\
\hline 3 & PDADMATFSI + 1.0 M LiTFSI in PY14TFSI & $1.0(\mathrm{RT})$ & - & 1400 & 400 (30th cycle) & 1.0 & $0.1 \mathrm{C}$ & [62] \\
\hline 4 & PVDF + 1.0 M LiTFSI + 0.4 $\mathrm{M} \mathrm{LiNO}_{3}$ in DOL/DME & $3.0\left(70^{\circ} \mathrm{C}\right)$ & 0.45 & 1675. & 1000 (100th cycle) & 2.0 & $56 \mathrm{~mA} \mathrm{~g}^{-1}$ & [63] \\
\hline 5 & $\mathrm{PVDF} / \mathrm{PEO} / \mathrm{ZrO}_{2}+1.0 \mathrm{M}$ LiTFSI in DOL/DME & $0.53\left(25^{\circ} \mathrm{C}\right)$ & 0.71 & 1058 & 847 (500th cycle) & 1.7 & $1.0 \mathrm{C}$ & [64] \\
\hline 6 & PDADMATFSI + 1.0 M LiTFSI in EMIM-TFSI & - & - & 693 & 142 (500th cycle) & - & $0.5 \mathrm{C}$ & {$[65]$} \\
\hline 7 & PVDF/PDA + 1.0 M LiTFSI in DOL/DME & $0.57(\mathrm{RT})$ & - & 1215 & 869 (200th cycle) & $1.0-1.3$ & $0.1 \mathrm{C}$ & [66] \\
\hline 8 & PETEA/Ester + 1.0 M LiTFSI in DOL/TEGDME + 1 wt. $\% \mathrm{LiNO}_{3}$ & $0.28(\mathrm{RT})$ & - & 713 & 499 (300th cycle) & $1.0-1.2$ & $0.5 \mathrm{C}$ & [67] \\
\hline 9 & PVDF-HFP/Fumed $\mathrm{SiO}_{2}+1.0 \mathrm{M} \mathrm{LiTFSI}+0.1 \mathrm{M} \mathrm{LiNO}_{3}$ in DOL/DME & $1.3\left(25^{\circ} \mathrm{C}\right)$ & - & 895 & 845 & $1.5-2.0$ & $0.1 \mathrm{C}$ & [68] \\
\hline 10 & $\mathrm{PPC} / \mathrm{SiO}_{2}+1.0 \mathrm{M} \mathrm{LiTFSI} \mathrm{in} \mathrm{DOL/TEGDME} \mathrm{+} 1$ wt. $\% \mathrm{LiNO}_{3}$ & $0.16\left(23^{\circ} \mathrm{C}\right)$ & 0.83 & 1672 & 1422 (500th cycle) & - & $100 \mathrm{~mA} \mathrm{~g}^{-1}$ & [69] \\
\hline 11 & PAN/PEO/LATP + 1.0 M LiTFSI in DOL/DME + 1 wt. $\% \mathrm{LiNO}_{3}$ & $0.86\left(25^{\circ} \mathrm{C}\right)$ & 0.55 & 904 & 704 (100th cycle) & $1.0-1.3$ & $0.1 \mathrm{C}$ & [70] \\
\hline 12 & PVDF-HFP/PETT-Ester + 1.0 M LiTFSI in DOL/DME + $1 \mathrm{wt} . \% \mathrm{LiNO}_{3}$ & $0.34\left(25^{\circ} \mathrm{C}\right)$ & 0.39 & 601 & 415 (300th cycle) & 1.2 & $0.5 \mathrm{C}$ & [71] \\
\hline 13 & $\mathrm{PMIA} / \mathrm{DDSDHE}+1.0 \mathrm{M} \mathrm{LiTFSI}+0.1 \mathrm{M} \mathrm{LiNO}_{3}$ in DOL/DME & 1.8 & - & 1122 & 713 (600th cycle) & 1.2 & $0.5 \mathrm{C}$ & {$[72]$} \\
\hline 14 & PVDF/OP + 0.6 M LiTFSI + 0.4 M LiNO $\mathrm{LiNO}_{3}$ in DOL/DME & $0.71\left(25^{\circ} \mathrm{C}\right)$ & 0.58 & 843 & 484 (300th cycle) & 2.0 & $0.5 \mathrm{C}$ & [73] \\
\hline 15 & PEGDA-P(VCA-co-BA $)+1.0 \mathrm{M} \mathrm{LiTFSI} \mathrm{in} \mathrm{DOL/DME} \mathrm{+} 1$ wt. $\% \mathrm{LiNO}_{3}$ & 2.9 & 0.63 & 1080 & 715 (300th cycle) & 4.5 & $0.1 \mathrm{C}$ & [74] \\
\hline
\end{tabular}

${ }^{[a]}$ Ionic conductivity. ${ }^{[b]}$ Lithium-ion transference number. ${ }^{[c]}$ Initial capacity. ${ }^{[\mathrm{dd}]}$ End of life capacity. ${ }^{[\mathrm{e}]}$ Sulfur loading. DDSDHE: di-(2-(5,5-dimethyl-2-sulfido-1,3,2-dioxaphosphinan-2-yl)hydrazineyl)-P-ethylphosphinic; DME: 1,2-dimethoxyethane; DOL: 1,3-dioxolane; LAGP: Li $\mathrm{i}_{1.5} \mathrm{Al}_{0.5} \mathrm{Ge}_{1.5}\left(\mathrm{PO}_{4}\right)_{3}$; EMIM-TFSI: ethylmethylimidazolium bis(tifluoromethanesulfonyl)imide; LATP: Li ${ }_{1.3} \mathrm{Al}_{0.3} \mathrm{Ti}_{1.7}\left(\mathrm{PO}_{4}\right)_{3}$; LiTFSI: lithium bis(trifluoromethanesulfonyl)imide; OP: organo-polysulfides; PDA: polydopamine; PEO: poly(ethylene oxide); PEGDA: poly(ethylene glycol) diacrylate; PDADMATFSI: poly(diallyldimethylammonium) bis(trifluoromethane) sulfonimide; PETEA: pentaerythritol tetraacrylate; PETT: pentaerythritol tetrakis(3-mercaptopropionate); P(VCA-co-BA): poly(vinyl carbonate-co-butyl acrylate); PVDF: poly(vinylidene fluoride); PVDF-HFP: poly(vinylidene fluoride-hexafluoropropylene); PY14TFSI: 1-methyl-1-butylpyrrolidinium bis(trifluoromethanesulfonyl)imide; RT: room temperature; TEGDME: tetraethylene glycol dimethyl ether.

electrochemical performance and becomes a safety hazard during battery operation ${ }^{[75]}$. In addition, these methods generally present wettability issues due to the poor contact between both components, especially in high-loading Li-S carbon-based porous cathodes, leading to poor interfacial contact and battery cyclability, as shown in Figure $2 \mathrm{~A}^{[76]}$.

Therefore, it is clear that the development of QSSPEs can simultaneously provide enhanced interfacial properties, improved safety and simple and effective preparation methods for large-scale applications that are essential. In this scenario, chemical methods, also known as "in-situ synthesis", are considered as the most promising alternatives. As shown in Figure $2 \mathrm{~B}$, these techniques can greatly improve the interfacial compatibility, owing to the intimate contact established between the electrodes, thereby providing an uninterrupted flow channel for lithium ions ${ }^{[76]}$. Likewise, the low cost, high efficiency and fabrication speed of these methods make them compatible with battery assembling processes. Different $i n$-situ preparation methods have been used in the literature in 
A
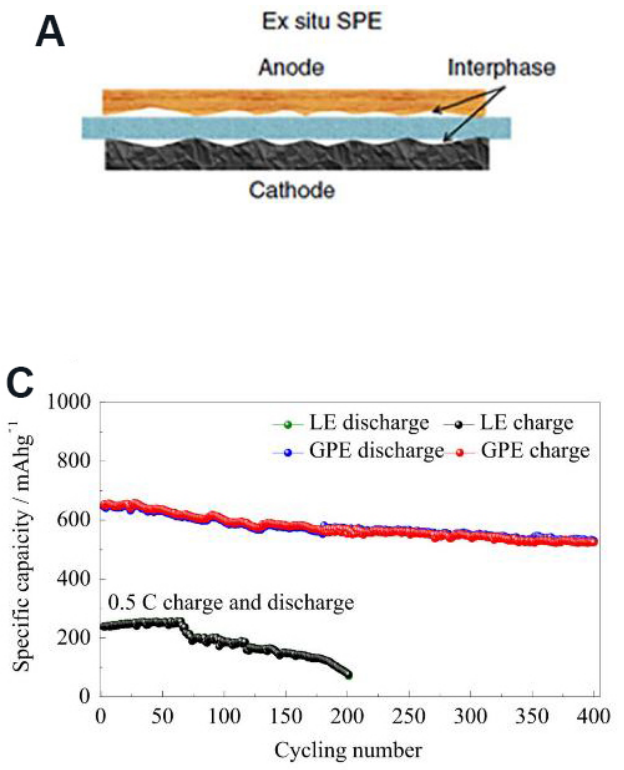

E

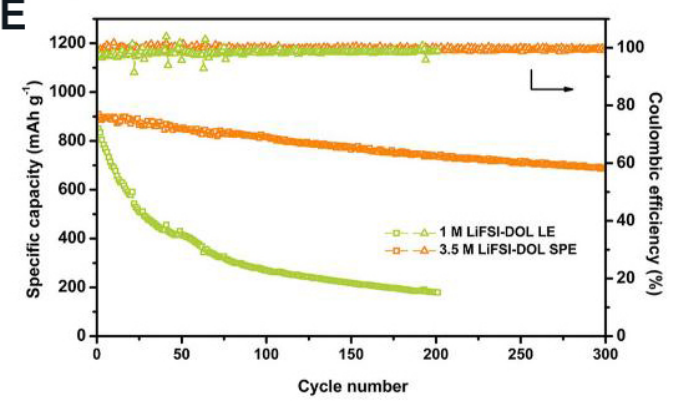

B

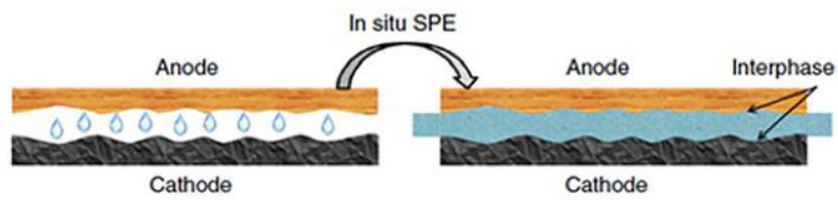

$\mathbf{F}$

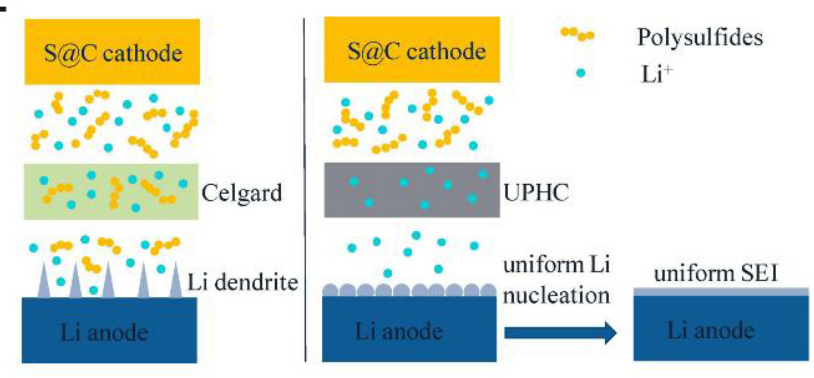

Figure 2. Schematic illustration of (A) ex-situ and (B) in-situ synthesis and the interfacial contact with the different cell elements. Figure 2A and B are reproduced from Ref. ${ }^{[76]}$ with permission. Copyright 2021 Wiley-VCH. (C) Comparison of Li-S cycling performance between LE and thermal crosslinked QSSE at 0.5 C. Reproduced from Ref. ${ }^{[60]}$ with permission. Copyright 2016 Elsevier. (D) Galvanostatic cycling of Li I| Li symmetric cell of $1 \mathrm{M} \mathrm{LiFSI-DOL-based} \mathrm{LE}\left(2 \mathrm{~mA} \mathrm{~cm}{ }^{-2}\right.$ and $\left.2 \mathrm{mAh} \mathrm{cm}{ }^{-2}\right)$ and $3.5 \mathrm{M} \mathrm{LiFSI-DOL-based}$ QSSE ( $2 \mathrm{~mA} \mathrm{~cm}^{-2}$ and $2 \mathrm{mAh} \mathrm{cm}^{-2}$, and $5 \mathrm{~mA} \mathrm{~cm}^{-2}$ and $5 \mathrm{mAh} \mathrm{cm}^{-2}$ ). (E) Cycling performance of $1 \mathrm{M} \mathrm{LiFSI-DOL-based} \mathrm{LE} \mathrm{and} 3.5 \mathrm{M}$ LiFSI-DOL-based QSSE at 0.2 C. Figure 2D and E are reproduced from Ref. ${ }^{[7]}$ with permission. Copyright 2021 Elsevier. (F) Schematic illustration of Li nucleation and PS diffusion in S@C/LE/Li and S@C/UPHC-QSSE/Li. Reproduced from Ref. ${ }^{[79]}$ with permission. Copyright 2020 Elsevier.

recent years, with three of them being particularly important for their application in Li-S batteries: thermochemical cross-linking, room temperature polymerization and ultraviolet (UV) induced crosslinking.

Of these three methods, thermochemical crosslinking, which consists of the formation of a threedimensional (3D) polymer network structure via a thermally induced free radical reaction, is by far the most used and analyzed method due to its simplicity and reproducibility. Liu et al. ${ }^{[00]}$ reported a QSSPE, prepared by in-situ synthesis with pentaerythritol tetraacrylate, which presented a remarkably high ionic conductivity of $1.13 \times 10^{-2} \mathrm{~S} \mathrm{~cm}^{-1}$ at RT. This, in combination with the ability to retain polysulfides, resulted in a highperformance Li-S cell with remarkable rate performance $\left(\sim 600 \mathrm{mAh} \mathrm{g}^{-1}\right.$ at $\left.1 \mathrm{C}\right)$ and capacity retention ( $81.9 \%$ after 400 cycles at $0.5 \mathrm{C}$ ), as displayed in Figure $2 \mathrm{C}$. However, this method requires the use of azobisisobutyronitrile as an initiator, which can cause stability issues due to its reactivity with the $\mathrm{Li}^{\circ}$ anode. 
With the aim of solving the reactivity issue of thermal initiators with $\mathrm{Li}^{\circ}$, researchers have made significant efforts to move to RT polymerization without the need to incorporate any type of initiator. This kind of synthesis method seeks to save energy during the process and also avoids the possible side reactions due to the non-reacted initiators. Cheng et al. ${ }^{[77]}$ reported a resourceful initiator-free gelation method by the ringopening polymerization of DOL. This work demonstrates a superior dendrite-free behavior, as shown in Figure $2 \mathrm{D}$, and good compatibility in a Li-S battery, delivering a capacity of $687 \mathrm{mAh} \mathrm{g}^{-1}$ after 300 cycles (capacity retention of $76 \%$ ) with a CE of $99.6 \%$ [Figure 2E].

Finally, although it is sometimes not strictly considered an in-situ technique due to the difficulty of applying it in preassembled cells, the UV light-induced crosslinking method, commonly used in the ink industry, has become greatly important both at the academic and industrial levels ${ }^{[78,79]}$. This method has attracted attention mainly for its low cost, reduction or even elimination of the use of solvents and its low energy consumption. In recent years, the group of Tu have carried out extensive studies on a modified poly(vinylidene fluoride)-co-hexafluoropropylene (PVDF-HFP)-based GPE with a 3D network constructed from the photopolymerization of pentaerythritol tetrakis-divinyl adipate (PETT-DA). This 3D network results in the diminished formation of dendrites and the "shuttle effect" [Figure 2F], while PVDF-HFP guarantees the mechanical properties of the $\mathrm{GPE}^{[71,79,80]}$. In addition to academic studies, the practical application of in-situ synthesis techniques has also been studied at an industrial level. Miltec successfully proved the viability of in-situ light-induced crosslinking for both electrode and QSSPE manufacturing for lithium-metal batteries (including Li-S batteries). These industrial initiatives represent a significant boost to finally demonstrating the industrial viability of these electrolytes for Li-S batteries.

Other than the preparation methods of QSSPEs, the electrolyte components, including plasticizers and polymer matrices, are also important to determine the electrochemical performance of a Li-S cell. In the literature, research attention has been focused on the investigation of different polymer hosts while using the standard state-of-the-art (SOA) LE as a plasticizer, i.e., DOL/DME-based electrolyte ${ }^{[13]}$. As a consequence, the "shuttle effect", the intrinsic issue of Li-S technology, still remains when using such QSSPEs. In order to tackle this challenge, in addition to carbon composites that can capsulate sulfur, avoiding the migration of polysulfides, different studies have intended to replace the elemental sulfur $\left(\mathrm{S}_{8}\right)$ by organosulfur as the active material in quasi-solid-state Li-S cells. These compounds consist of sulfur chains of variable sizes covalently bonded with organic frameworks.

The main example is the widely used sulfurized polyacrylonitrile (SPAN). Figure 3A shows a schematic illustration of the differences between the redox process of elemental sulfur and SPAN. The first discharge plateau disappears when using SPAN in the cell, which is related to the solid to solid reaction and the absence of solubilized long chain PS in the electrolyte, leading to a very stable performance and high specific capacity ${ }^{[81,82]}$. In the work of Liu et al. ${ }^{[83]}$, SPAN was prepared by heating sulfur powder and polyacrylonitrile (PAN) at $300{ }^{\circ} \mathrm{C}$ under an argon atmosphere and this material was coupled with a QSSPE to obtain long cycling and a high capacity ( $550 \mathrm{mAh} \mathrm{g}^{-1}$ in the first cycle and $500 \mathrm{mAh} \mathrm{g}^{-1}$ after 180 cycles $)$ at $50{ }^{\circ} \mathrm{C}$ [Figure $3 B$ ] . Since this work, many studies have been developed in order to improve its performance ${ }^{[84]}$. However, there are still improvements to be made, especially in the case of high sulfur compositions (> $50 \mathrm{wt} . \%$ ) in the chemical structure of the organosulfur, due to the persistence of long chain PS formation, as illustrated in Figure $3 C^{[85]}$. In order to solve the persistent "shuttle effect", new organosulfur structures have been developed recently, such as the one presented by Yan et al. ${ }^{[86]}$. This compound, based on fluorinated quinone with a high S content, shows an outstanding performance of $\sim 800 \mathrm{mAh} \mathrm{g}^{-1}$ of sulfur (560 $\mathrm{mAh} \mathrm{g}^{-1}$ of organosulfur) after 600 cycles at $0.5 \mathrm{C}$ [Figure 3D]. 

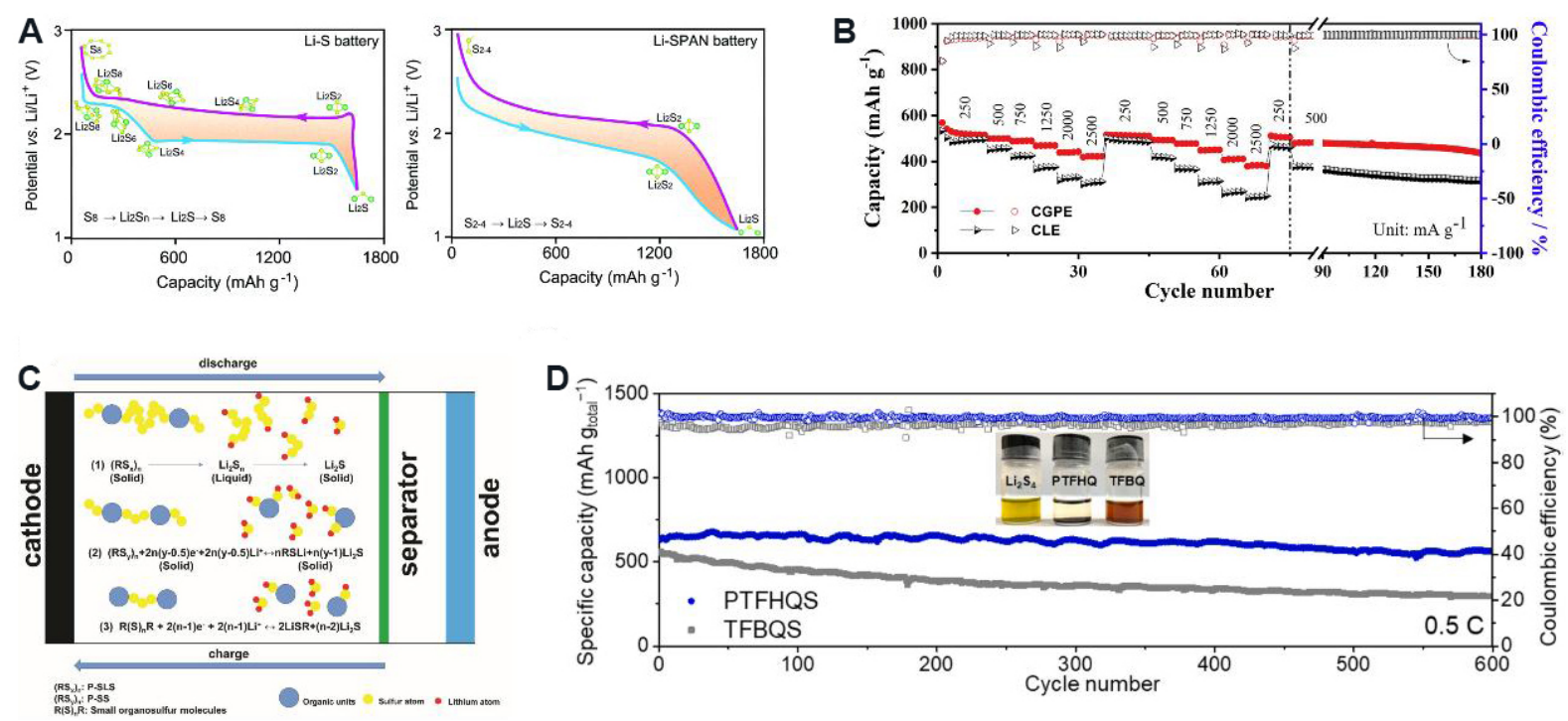

Figure 3. (A) Schematic illustration of the different redox reactions between Li-S and Li-SPAN batteries. Reproduced from Ref. ${ }^{[81]}$ with permission. Copyright 2021 Royal Society of Chemistry. (B) Electrochemical performance of SPAN-based cathode material at $50{ }^{\circ} \mathrm{C}$ using a LE or GPE at different C-rates and long cycles. Reproduced from Ref. ${ }^{[83]}$ with permission. Copyright 2019 Cell Press. (C) Different electrochemical processes depending on the $S$ content in the organosulfur structure. Reproduced from Ref. ${ }^{[85]}$ with permission. Copyright 2020 Royal Society of Chemistry. (D) Long cycling performance for recently developed fluorinated organosulfur quinone at 0.5 C. Reproduced from Ref. ${ }^{[86]}$ with permission. Copyright 2019 American Chemical Society.

\section{PROJECTED ENERGY DENSITY AND PERSPECTIVES}

Most of the abovementioned work on Li-S cells using ASSPEs and QSSPEs is mainly focused on materials development and selection. With regards to practical applications, it is important to know the potential energy density that can be achieved using different types of electrolytes and the key parameters required to reach the target energy density. Herein, estimations of the energy density of Li-S cells, as shown in Figure 4, have been carried out under realistic conditions (e.g., S utilization, loading and negative to positive capacity ratio), with variation of the thickness ( $t$ ) of the electrolyte membrane in the case of ASSPEs and liquid content in the case of QSSPEs. In order to assess the energy density at the cell level, the following formula was utilized:

$$
\mathrm{E}_{\text {cell }}^{\mathrm{g}}=\frac{\mathrm{C}_{\text {cell }}^{\mathrm{a}} \cdot \mathrm{V}_{\text {cell }}}{\mathrm{m}_{\text {cell }}^{\mathrm{a}}}
$$

where $\mathrm{C}_{\text {cell }}^{\mathrm{a}}$ is the areal capacity of the cell, $\mathrm{V}_{\text {cell }}$ is the average discharge voltage and $\mathrm{m}_{\text {cell }}^{\mathrm{a}}$ is the sum of the areal mass of every cell component, including the current collector, separator (when necessary), anode, cathode and electrolyte.

The estimation of different electrolytes was carried out using different methods. For ASSPEs, the mass $\left(\mathrm{m}_{\text {elec }}^{\mathrm{a}}\right)$ is calculated by the product of the electrolyte thickness $\left(\mathrm{t}_{\text {elec }}\right)$, the density of PEO $\left(\rho_{\text {elec }}\right)$ and porosity: $\mathrm{m}_{\text {elec }}^{\mathrm{a}}=\mathrm{t}_{\text {elec }} \cdot \rho_{\text {elec }} \cdot\left(1-\varepsilon_{\text {elec }}\right)$. For LEs, the mass of the electrolyte is obtained considering the areal sulfur loading $\left(\mathrm{m}_{\mathrm{s}}^{\mathrm{a}}\right)$, the electrolyte to sulfur ratio $(\mathrm{E} / \mathrm{S})$ and the electrolyte density $\left(\rho_{\text {elec }}\right): \mathrm{m}_{\text {elec }}^{\mathrm{a}}=\mathrm{m}_{\mathrm{s}}^{\mathrm{a}} \cdot \mathrm{E} / \mathrm{S} \cdot \rho_{\text {elec }}$. Finally, for QSSPEs, a combined strategy was followed. Initially, the mass of the solid membrane was calculated for a PVDF membrane, following the strategy of ASSPEs. Additional LE mass added to wet this membrane was then calculated based on this mass. Furthermore, the additional LE to wet the cathode was calculated based 

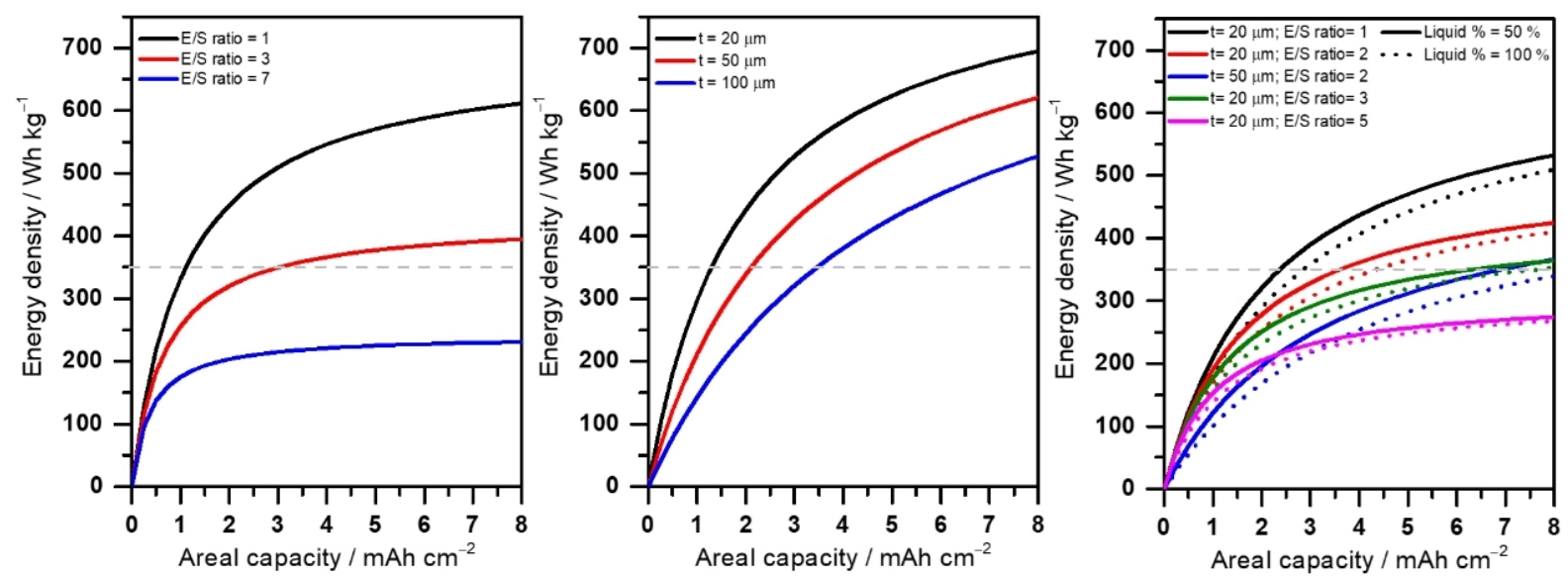

Figure 4. Energy density estimations for ASSPE-, QSSPE- and LE-based Li-S cells with various electrolyte thicknesses ( $t$, in ASSPE systems), liquid content (wt.\%, in QSSPE systems) and E/S ratios (in LE systems). Calculations were performed with the following parameters: $1200 \mathrm{mAh} \mathrm{g}_{\text {sulfur }}{ }^{-1}$ for cathode capacity; 64 wt.\% sulfur loading for LE and 50 wt.\% sulfur loading for ASSPE Li-S cells. In all the cases, the negative to positive capacity ratio was set to 3 .

on the E/S ratio, as for LEs. Liquid systems are not the focus of this perspective but they are also included as a reference for comparison.

\section{ASSPE systems}

It has been shown that Li-S technology is not competitive with SOA Li-ion cells in terms of volumetric energy density; therefore, the estimations of energy density shown in Figure 4 include only gravimetric values based on the total weight of the cell components (without packaging). A target of $350 \mathrm{Wh} \mathrm{kg}^{-1}$ was chosen to surpass today's SOA Li-ion batteries at the cell level. To reach this value, in the case of Li-S cells with ASSPEs, the electrolyte membrane must go down to $50 \mu \mathrm{m}$, with a cathode of $2 \mathrm{mAh} \mathrm{cm}^{-2}$. This seems more feasible compared to liquid systems, where an E/S ratio of $3 \mu \mathrm{L} \mathrm{mg}^{-1}$ and an areal capacity of > $3 \mathrm{mAh} \mathrm{cm}^{-2}$ are needed in order to reach $350 \mathrm{Wh} \mathrm{kg}^{-1}$. This difference between both systems is explained by the double role of the ASSPE in both the cathode and electrolyte. In the cathode, the ASSPE acts as both a binder and catholyte, wetting electrode materials and eliminating the need for any additional electrolyte. In the electrolyte, the ASSPE not only conducts $\mathrm{Li}^{+}$, but is also used as a physical barrier between two electrodes to prevent short circuiting of the cell (no additional separator is needed). This allows for a reduction in the weight of the inert compounds, thereby increasing the energy density of the system.

However, experiments have suggested that, when a ASSPE-based Li-S cell is coupled with a bench-marking cathode, which has been optimized based on the parameters of a LE, reaching an areal capacity of $>$ $2 \mathrm{mAh} \mathrm{cm}^{-2}$ is rather challenging ${ }^{[19]}$. This is due to the fact that the intrinsic properties of ASSPE systems that determine the $\mathrm{S}$ utilization are different from LEs, i.e., viscosity, wettability and ionic conductivity, leading to different optimum conditions of pore size and porosity in the cathode. When studying ASSPEs for Li-S cells, the cathode limitations should be taken into consideration to interpret the results. Unlike liquid-based Li-S systems, where the cathode is no longer an issue after decades of development, the optimization of cathodes for ASSPE-based Li-S cells should be conducted and extended in order to reach

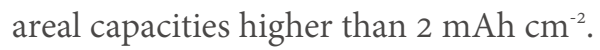

\section{QSSPE systems}

To decrease the operating temperature of ASSPE-based Li-S cells, QSSPEs were used to increase the ionic conductivity at RT, whilst simultaneously providing improved safety compared to LE-based cells. In QSSPE 
based Li-S cells, due to the presence of the liquid phase plasticizer, the cathode used is the same as the ones in LE-based Li-S cells in terms of formulation. Hence, the estimations of energy density of QSSPE-based Li$\mathrm{S}$ cells consider the parameters of both the catholyte (E/S ratio) and electrolyte (liquid content and thickness of the electrolyte membrane).

The results clearly show that the amount of liquid in the electrolyte varying from 50 to $100 \mathrm{wt} . \%$ does not have a significant impact on the energy density. On the contrary, the E/S ratio of the catholyte and the thickness of the electrolyte dominate the variation of the total weight of the cell. Comparably to the LE system, in QSSPE-based Li-S cells, if the electrolyte membrane thickness is $20 \mu \mathrm{m}$ with a catholyte E/S ratio of 1 or 2 , the areal capacity should be between 2.5 and $4 \mathrm{mAh} \mathrm{cm}^{-2}$ in order to reach the targeted $350 \mathrm{Wh} \mathrm{kg}^{-1}$. Unfortunately, current QSSPE-based Li-S cells are not able to achieve these criteria. Note that, even for Li-S cells comprising bench-marking DME/DOL-based LEs, it is still a challenge to operate for more than 100 cycles with such criteria values at a large pouch level ${ }^{[87-91]}$. Noteworthy, due to the presence of the liquid phase in the QSSPE system, the discharge/charge reaction and the Li/electrolyte interface are comparable to the LE system. Therefore, although the LEs for Li-S cells are not the main focus of this perspective, it is important to provide a brief discussion of LEs as plasticizers in QSSPEs.

It is generally accepted that Li-S cell failure is mainly due to Li anode degradation or consumption ${ }^{[87,92-94]}$. Following this conclusion, studies have focused on Li protection development, including in-situ SEI formation by additives, ex-situ protection by different coatings and 3D Li metal anodes. Nevertheless, the effectiveness of these approaches is questionable due to the dynamic Li stripping and plating on the $\mathrm{Li}$ anode upon cycling (cracks occur on the SEI and coatings) and the high reactivity between Li and the electrolyte (even higher when increasing the surface area in the case of 3D Li metal), with the LE possibly being the most decisive cell component to determine the electrochemical performance. Nevertheless, the reported developments of QSSPEs for Li-S cells mainly concentrate on preparation methods and the selection of new materials as polymer matrices ${ }^{[95]}$. More attention should therefore be paid to plasticizers, which are equally or even more critical for QSSPE-based Li-S cell performance. Currently, 1 M LiTFSI in a binary mixture of DME/DOL $(1: 1 \mathrm{v} / \mathrm{v})$ containing $\mathrm{LiNO}_{3}$ as an additive is widely regarded as a benchmark for QSSPE-based Li-S cells. The introduction of $\mathrm{LiNO}_{3}$ significantly improves the interfacial stability of the lithium anode through the in-situ formation of a favorable SEI, which facilities homogeneous and dendritefree Li deposition and a highly reversible plating/stripping process. Inspired by this principle, all the valuable salts and additives reported in ASSPE-based Li-S cells can also be employed in QSSPE-based systems, such as LiDFTFSI, LiTCM and $\mathrm{LiN}_{3}$, to regulate the Li deposition and form excellent SEI layers ${ }^{[13]}$.

As discussed above, the commonly used solvents for QSSPE-based Li-S cells are ether solvents, such as DME and DOL. However, the intermediate PS are prone to dissolution in ether-based solvents, followed by shuttling from the sulfur cathode to lithium anode during the repeat charge/discharge process, leading to a fast capacity decay. It is reported that ionic liquids (ILs) with high viscosity can effectively diminish the "shuttle effect" due to the low solubility of PS in ILs ${ }^{[19]}$. Furthermore, the Lewis acid cations of ILs are capable of effectively trapping PS from diffusion based on the hard and soft acid and base theory, which also contributes to suppressing PS shuttle ${ }^{[96]}$. Therefore, QSSPE-based Li-S cells comprising IL-based plasticizers showed good sulfur utilization and capacity retention at lower C-rates $(<0.5 \mathrm{C})$. However, IL-based QSSPEs show a lower ionic conductivity compared to ether-based ones, resulting in inferior electrochemical performance when a high current density is applied ${ }^{[13]}$.

Beyond the SOA DME/DOL LE, which has a high solubility of PS (near $7 \mathrm{M}$ ), another type of LE with a limited or absent solubility of PS has also been investigated. The simplest approach is to increase the Li salt 
concentration from 1 to $7 \mathrm{M}$ while using the same DME/DOL solvent ${ }^{[97-99]}$. However, the density and viscosity of such electrolytes are very high and the cost is also simultaneously dramatically increased. Consequently, Cuisinier et al. ${ }^{[100]}$, Lee et al. ${ }^{[101]}$, Shyamsunder et al. ${ }^{[102]}$ proposed new different concepts of "sparingly solvating electrolytes", which consists of a low donor number solvent as a co-solvent or as a solo solvent when a low ion-pairing Li salt is used. Following this concept, other research groups, such as Nakanishi et al. in Japan and Piwko et al. in Germany, also actively contributed to this regard ${ }^{[103-107]}$. It is noteworthy that with the change from electrolytes with high PS solubility to such "sparingly solvating electrolytes", the whole cell chemistry is changed simultaneously. Indeed, the discharge/charge profile of S cathodes using such electrolytes is distinct compared to the DME/DOL system. Although the formation of long chain PS still occurs, their conversion to shorter chain PS is instantaneous due to the limited solubility of long chain PS in the electrolyte. This change in S reduction mechanism results in a difference in the optimum condition of the cathode in terms of porosity, pore size and E/S ratio. Moreover, the absence of long chain PS in the electrolyte could also affect the Li/electrolyte interface, meaning less harsh conditions for Li metal.

It is still too early to draw a conclusion of whether "sparingly solvating electrolytes" will enable a long cycle life Li-S cell with competitive gravimetric energy density but this kind of LE can be an option as a plasticizer for QSSPEs. As discussed earlier, in order to study the real effect of such QSSPEs, the cathode should not be a limiting factor, which needs to be suitable for "sparingly solvating electrolytes". Furthermore, although the amount of the liquid content (50 or $100 \mathrm{wt} . \%$ ) in the QSSPE does not remarkably affect the energy density of the cell, it does have a significant impact on the Li/electrolyte interface. All the above-mentioned aspects need to be taken into consideration when designing a QSSPE-based Li-S cell using "sparingly solvating electrolytes" as plasticizers.

\section{CONCLUSION AND OUTLOOK}

This perspective has briefly summarized the recent progress on polymer-based solid-state Li-S batteries, with a special focus on the electrolytes, including all-solid-state polymer electrolytes (ASSPEs) and quasisolid-state polymer electrolyte (QSSPEs). Advances have been mainly made in tuning the anion chemistry in ASSPEs, with the aim of forming a robust SEI on the Li anode to improve the stability of the cell and enable a long cycle life. The majority of published studies of QSSPE-based Li-S cells are related to the preparation method to achieve a facile, cost-effective, eco-friendly and scalable processing route. Moreover, strategies for improving Li/electrolyte interfaces have also been addressed in numerous works through the enhancement of the physical contact between the QSSPE and Li anode using an appropriate preparation method. Despite the aforementioned improvements in both ASSPE- and QSSPE-based Li-S cells, the cycling performances (especially the cells with a high S loading) of these two electrolyte-based cells are still far from the LE-based one [Table 2]. These can be attributed to the following issues and challenges: (1) low ionic conductivity at room temperature, especially for ASSPE-based cells; (2) uncontrollable dissolution and "shuttle effect" of polysulfides (PS); (3) adverse electrode/electrolyte interfaces, e.g., inferior chemical/electrochemical stability. To make them competitive with LE-based Li-S cells and enhance the overall performance of ASSPE- and QSSPE-based Li-S cells, the following aspects are critical:

(1) The role of salt anions in dictating the properties of the electrolytes and electrolyte/electrode interfaces has been spotlighted in ASSPE-based Li-S cells. Designing and developing novel lithium salt anions with super-delocalized structure and superior SEI (or CEI) formation properties is of paramount significance, which not only facilities enhanced ionic conductivity but also boosts the formation of excellent interfaces. 
Table 2. Comparison of ASSPE-, QSSPE- and LE-based Li-S cells

\begin{tabular}{|c|c|c|c|c|c|c|c|c|}
\hline Electrolytes & Cathode composition/wt.\% & $\mathrm{SL}^{[\mathrm{a}]} / \mathrm{mg} \mathrm{cm}^{-2}$ & Electrolyte composition & $\mathrm{IC}^{[\mathrm{b}]} / \mathrm{mAh} \mathrm{g}^{-1}$ & $\mathrm{FC}^{[\mathrm{cc}]} / \mathrm{mAh} \mathrm{g}^{-1}$ & Rate & Cycle life & Ref. \\
\hline \multirow[t]{5}{*}{ ASSPES } & $S(40)+K B(15)+S E(45)$ & $1 \pm 0.1$ & PEO/LiFSI & 550 & 100 & $0.1 \mathrm{C}$ & 1000 & {$[35]$} \\
\hline & $S(40)+K B(15)+S E(45)$ & $1 \pm 0.1$ & PEO/LiFTFSI & 790 & 626 & $0.1 \mathrm{C}$ & 50 & [43] \\
\hline & $S(40)+K B(15)+S E(45)$ & $1 \pm 0.1$ & PEO/LiDFTFSI & 600 & 150 & $0.1 \mathrm{C}$ & 1300 & [39] \\
\hline & $S(40)+K B(15)+S E(45)$ & $1 \pm 0.1$ & PEO/LiTFSI + 10\% LiDFTFSI & 810 & 400 & $0.1 \mathrm{C}$ & 100 & [38] \\
\hline & $S @ K B(80)+A B(10)+P V D F(10)$ & $0.6-1.0$ & $\mathrm{PEO} / \mathrm{LiClO}_{4}$ & 600 & 600 & $0.1 \mathrm{C}$ & 30 & [108] \\
\hline \multirow[t]{5}{*}{ QSSPES } & S@CMK-3 (80)+AB (10)+PVDF (10) & $1.2-1.5$ & PETEA activated in $1 \mathrm{M} \mathrm{LiTFSI-DME/DOL}+1 \% \mathrm{LiNO}_{3}$ & 650 & 580 & $0.5 \mathrm{C}$ & 400 & {$[60]$} \\
\hline & S@CNT (90)+PVDF (10) & 4.9 & $\mathrm{PEO} / \mathrm{LiTFSI}$ activated in $1 \mathrm{M}$ LiTFSI-DME/DOL + $1 \% \mathrm{LiNO}_{3}$ & 850 & 600 & $0.1 \mathrm{C}$ & 50 & [109] \\
\hline & $S @ A B(80)+A B(10)+P V D F(10)$ & $1.5-2.0$ & PETT-DA + PVDF activated in $1 \mathrm{M} \mathrm{LiTFSI-DME/DOL}+2 \% \mathrm{LiNO}_{3}$ & 700 & 620 & $0.5 \mathrm{C}$ & 300 & [79] \\
\hline & $\operatorname{SPAN}(60)+A B(30)+P A N(10)$ & N/A & $\mathrm{LiPF}_{6}-\mathrm{EC} / \mathrm{DMC} / \mathrm{DEC}$ & 1200 & 975 & N/A & 50 & [83] \\
\hline & $S(60)+A B(30)+P V D F(10)$ & 4 & LiTFSI/DOL polymerization & 700 & 600 & N/A & 80 & {$[77]$} \\
\hline \multirow[t]{5}{*}{ LEs } & $S @ A B(80)+A B(20)+P G(10)$ & 9 & $1 \mathrm{M} \mathrm{LiTFSI-DME} / \mathrm{DOL}+2 \% \mathrm{LiNO}_{3}$ & 855 & 500 & $0.13 \mathrm{C}$ & 40 & [110] \\
\hline & $\mathrm{S}(70)+\mathrm{C}(20)+\mathrm{CMC} / \mathrm{Gl}(6.7 / 3.3)$ & 6.5 & 0.5 M LiTFSI-0.5 M LiNO 3 -DME/DOL & 1320 & 1100 & $0.1 \mathrm{C}$ & 120 & [111] \\
\hline & $\mathrm{S} @ \mathrm{CoS}_{2}-\mathrm{G}(80)+\mathrm{KN}(10)+\mathrm{PVDF}(10)$ & 2.9 & $1 \mathrm{M} \mathrm{LiTFSI-DME} / \mathrm{DOL}+1 \% \mathrm{LiNO}_{3}$ & 1100 & 820 & $0.2 \mathrm{C}$ & 30 & [112] \\
\hline & $\mathrm{S}-\mathrm{Fe}-\mathrm{Ni}-\mathrm{NC}(60)+\mathrm{AB}(20)+\mathrm{PVDF}(10)$ & 4.1 & $1 \mathrm{M} \mathrm{LiTFSI-DME} / \mathrm{DOL}+0.1 \mathrm{M} \mathrm{LiNO}_{3}$ & 1000 & 580 & $1.0 \mathrm{C}$ & 800 & [113] \\
\hline & S@Co-N/G (75)+KB (15)+PVDF (10) & 6 & $1 \mathrm{M}$ LiTFSI-DME/DOL + 2\% $\mathrm{LiNO}_{3}$ & 850 & 833 & $0.2 \mathrm{C}$ & 100 & [114] \\
\hline
\end{tabular}

${ }^{[a]}$ Sulfur loading. ${ }^{[b]}$ Initial capacity. ${ }^{[c]}$ Final capacity. AB: Acetylene black; AM: active material; C: carbon; CMC: carboxymethyl cellulose; CMK-3: CMK-3 carbon; CNT: carbon nanotubes; Co-N-G: cobalt in nitrogendoped graphene; $\mathrm{COS}_{2}$-G: cobalt disulfide-graphene mixture; DA: divinyl adipate; DEC: diethylene carbonate; DMC: dimethyl carbonate; DEC: diethylene carbonate; DME: dimethoxyethane; DOL: dioxalane; EC: ethylene carbonate; Fe-Ni-NC: Fe-Ni nanoparticles encapsulated in nitrogen-doped carbon; G: graphene; Gl: glucose; KB: Ketjenblack; LiDFTFSI: lithium (difluoromethanesulfonyl) (trifluoromethanesulfonyl)imide; LiFSI: lithium bis(fluorosulfonyl)imide; LiFTFSI: lithium (fluorosulfonyl)(trifluoromethanesulfonyl)imide; LiTFSI: lithium bis(trifluorosulfonyl)imide; MWCNT: multi-walled carbon nanotubes; NC: nitrogen-doped carbon; NG: nitrogen-doped graphene; PAN: polyacrylonitrile; PEO: poly(ethylene oxide); PETEA: pentaerythritol tetraacrylate; PETT: pentaerythritol tetrakis; PG: peach gum; PVDF: polyvinylidene fluoride; PVDFHFP: poly(vinylidene fluoride)-co-hexafluoropropylene); S: sulfur; SE: solid electrolyte.

It is well anticipated that PS can be dissolved and diffuse easily in the PEO-based matrix. In pursuit of high-performance Li-S cells with paramount PS inhibition, new polymer hosts containing an oxygen/nitrogen functional group (e.g., - $\mathrm{O}-\mathrm{C}=\mathrm{O},-\mathrm{C}=\mathrm{O},-\mathrm{C}-\mathrm{O}-\mathrm{C}$, $-\mathrm{C}=\mathrm{N}$ and so on), which shows strong interactions with LiPS, are of interest for building excellent Li-S batteries. In addition, the development of single-ion conductive GPEs, which not only transport $\mathrm{Li}^{+}$but also block negatively charged LiPS, are gaining particular attention for overcoming the PS shuttle effect. In parallel, investigations of new plasticizers, e.g., "sparingly solvated electrolytes" and ionic liquids, should be more considered due to their key roles in terms of prolonging the cycle life of the practical large-scale cells, which is of a paramount challenge for Li-S technology. 
(3) A better understanding of the interfaces (e.g., SEI and CEI layers), particularly regarding their morphologies, compositions, formation mechanisms and properties, is essential. Both in the case of ASSPEs and in the case of QSSPEs, the use of advanced characterization techniques such as nuclear magnetic resonance, in-situ studies using X-ray photoelectron spectroscopy, electron microscopy (transmission or scanning), density functional theory calculations and so on, are highly recommended, as essential tools to understand and clarify the operational problems commonly associated with Li-S batteries. The understanding of the issues with these techniques would inspire potential strategy solutions. These improvements would definitively boost the long-awaited development of high-energy density polymerbased Li-S batteries.

(4) Future work should be conducted on the specific cathode development for ASSPE- and QSSPE-based Li-S cells in order to reach the requested criteria to surpass the competitive gravimetric energy density of $350 \mathrm{Wh} \mathrm{kg}^{-1}$ as indicated by estimations.

\section{DECLARATIONS}

\section{Authors' contributions}

Conceived the research and supervised the work: Li C, Zhang $\mathrm{H}$

Wrote the manuscript: Castillo J, Qiao L, Santiago A, Judez X, Sáenz de Buruaga A, Jiménez-Martín G, Armand M, Zhang H, Li C

Homogenized the final version and took a prominent role during the corrections: Qiao L, Castillo J

All authors have given approval to the final version of the manuscript.

\section{Availability of data and materials}

Not applicable.

\section{Financial support and sponsorship}

This project has received funding from the European Union's Horizon 2020 research and innovation program Graphene Flagship Core Project 3 (GrapheneCore3) under grant agreement 881603. This work is also supported by Ministerio de Ciencia, Innovación y Universidades (MCIU), a la Agencia Estatal de Investigación (AEI) y al Fondo Europeo de Desarrollo Regional (FEDER) (RTI2018-098301-B-Ioo). Castillo $\mathrm{J}$ is a beneficiary of the Predoctoral Program from the Education Department of the Basque Government. Zhang $\mathrm{H}$ thanks the financial support from the Fundamental Research Funds for the Central Universities, HUST (2020kfyXJJS095).

\section{Conflicts of interest}

All authors declared that there are no conflicts of interest.

\section{Ethical approval and consent to participate}

Not applicable.

\section{Consent for publication}

Not applicable.

\section{Copyright}

(c) The Author(s) 2022. 


\section{REFERENCES}

1. Cano ZP, Banham D, Ye S, et al. Batteries and fuel cells for emerging electric vehicle markets. Nat Energy 2018;3:279-89. DOI

2. Goodenough JB. How we made the Li-ion rechargeable battery. Nat Electron 2018;1:204-204. DOI

3. Armand M, Tarascon JM. Building better batteries. Nature 2008;451:652-7. DOI PubMed

4. Tarascon JM, Armand M. Issues and challenges facing rechargeable lithium batteries. Nature 2001;414:359-67. DOI PubMed

5. Shen Y, Zhang Y, Han S, Wang J, Peng Z, Chen L. Unlocking the energy capabilities of lithium metal electrode with solid-state electrolytes. Joule 2018;2:1674-89. DOI

6. Zhang H, Eshetu GG, Judez X, Li C, Rodriguez-Martínez LM, Armand M. Electrolyte additives for lithium metal anodes and rechargeable lithium metal batteries: progress and perspectives. Angew Chem Int Ed Engl 2018;57:15002-27. DOI PubMed

7. Choi JW, Aurbach D. Promise and reality of post-lithium-ion batteries with high energy densities. Nat Rev Mater 2016:1. DOI

8. Nazar LF, Cuisinier M, Pang Q. Lithium-sulfur batteries. MRS Bull 2014;39:436-42. DOI

9. Yin YX, Xin S, Guo YG, Wan LJ. Lithium-sulfur batteries: electrochemistry, materials, and prospects. Angew Chem Int Ed Engl 2013;52:13186-200. DOI PubMed

10. Bruce PG, Freunberger SA, Hardwick LJ, Tarascon JM. Li-O2 and Li-S batteries with high energy storage. Nat Mater 2011;11:19-29. DOI PubMed

11. Liu G, Sun Q, Li Q, Zhang J, Ming J. Electrolyte Issues in Lithium-Sulfur batteries: development, prospect, and challenges. Energy Fuels 2021;35:10405-27. DOI

12. Judez X, Zhang H, Li C, et al. Review - solid electrolytes for safe and high energy density lithium-sulfur batteries: promises and challenges. J Electrochem Soc 2017;165:A6008-16. DOI

13. Judez X, Martinez-ibañez M, Santiago A, Armand M, Zhang H, Li C. Quasi-solid-state electrolytes for lithium sulfur batteries: advances and perspectives. J Power Sources 2019;438:226985. DOI

14. Li S, Zhang W, Zheng J, Lv M, Song H, Du L. Inhibition of polysulfide shuttles in Li-S batteries: modified separators and solid-state electrolytes. Adv Energy Mater 2021;11:2000779. DOI

15. Yang X, Luo J, Sun X. Towards high-performance solid-state Li-S batteries: from fundamental understanding to engineering design. Chem Soc Rev 2020;49:2140-95. DOI PubMed

16. Tang S, Guo W, Fu Y. Advances in composite polymer electrolytes for lithium batteries and beyond. Adv Energy Mater 2021;11:2000802. DOI

17. Aziz SB, Woo TJ, Kadir M, Ahmed HM. A conceptual review on polymer electrolytes and ion transport models. Journal of Science: Advanced Materials and Devices 2018;3:1-17. DOI

18. Qian J, Jin B, Li Y, Zhan X, Hou Y, Zhang Q. Research progress on gel polymer electrolytes for lithium-sulfur batteries. Journal of Energy Chemistry 2021;56:420-37. DOI

19. Jiang M, Zhang Z, Tang B, et al. Polymer electrolytes for Li-S batteries: polymeric fundamentals and performance optimization. Journal of Energy Chemistry 2021;58:300-17. DOI

20. Qiao L, Judez X, Rojo T, Armand M, Zhang H. Review - polymer electrolytes for sodium batteries. J Electrochem Soc 2020;167:070534. DOI

21. Long L, Wang S, Xiao M, Meng Y. Polymer electrolytes for lithium polymer batteries. J Mater Chem A 2016;4:10038-69. DOI

22. Fang R, Xu H, Xu B, Li X, Li Y, Goodenough JB. Reaction mechanism optimization of solid-state Li-S batteries with a PEO-based electrolyte. Adv Funct Mater 2021;31:2001812. DOI

23. Liu Y, Liu H, Lin Y, et al. Mechanistic investigation of polymer-based all-solid-state lithium/sulfur battery. Adv Funct Mater 2021;31:2104863. DOI

24. Zhang Z, Zhao B, Zhang S, et al. A mixed electron/ion conducting interlayer enabling ultra-stable cycle performance for solid state lithium sulfur batteries. J Power Sources 2021;487:229428. DOI

25. Zhong L, Wang S, Xiao M, et al. Addressing interface elimination: boosting comprehensive performance of all-solid-state Li-S battery. Energy Storage Materials 2021;41:563-70. DOI

26. Xue Z, He D, Xie X. Poly(ethylene oxide)-based electrolytes for lithium-ion batteries. J Mater Chem A 2015;3:19218-53. DOI

27. Hong S, Wang Y, Kim N, Lee SB. Polymer-based electrolytes for all-solid-state lithium-sulfur batteries: from fundamental research to performance improvement. J Mater Sci 2021;56:8358-82. DOI

28. Eshetu GG, Judez X, Li C, et al. Ultrahigh performance all solid-state lithium sulfur batteries: salt Anion's chemistry-induced anomalous synergistic effect. J Am Chem Soc 2018;140:9921-33. DOI PubMed

29. Armand M, Gorecki W, Andreani R. Proceedings of the 2nd international meeting on polymer electrolytes. In: Scrosati B, editor. London: Elsevier; 1989. p. 91.

30. Qiao L, Oteo U, Zhang Y, et al. Trifluoromethyl-free anion for highly stable lithium metal polymer batteries. Energy Storage Materials 2020;32:225-33. DOI

31. Marmorstein D, Yu T, Striebel K, Mclarnon F, Hou J, Cairns E. Electrochemical performance of lithium/sulfur cells with three different polymer electrolytes. J Power Sources 2000;89:219-26. DOI

32. Park C, Ryu H, Kim K, et al. Effect of sulfur electrode composition on the electrochemical property of lithium/PEO/sulfur battery. Met Mater Int 2004;10:375-9. DOI

33. Shin J, Kim K, Ahn H, Ahn J. Electrochemical properties and interfacial stability of (PEO)10LiCF3SO3-TinO2n-1 composite polymer electrolytes for lithium/sulfur battery. Mater Sci Eng B 2002;95:148-56. DOI

34. Ma Q, Qi X, Tong B, et al. Novel Li $\left[\left(\mathrm{CF}_{3} \mathrm{SO}_{2}\right)\left(\mathrm{n}-\mathrm{C}_{4} \mathrm{~F}_{9} \mathrm{SO}_{2}\right) \mathrm{N}\right]$-based polymer electrolytes for solid-state lithium batteries with 
superior electrochemical performance. ACS Appl Mater Interfaces 2016;8:29705-12. DOI PubMed

35. Judez X, Zhang H, Li C, et al. Lithium Bis(fluorosulfonyl)imide/Poly(ethylene oxide) polymer electrolyte for all solid-state Li-S Cell. J Phys Chem Lett 2017;8:1956-60. DOI PubMed

36. Younesi R, Veith GM, Johansson P, Edström K, Vegge T. Lithium salts for advanced lithium batteries: Li-metal, Li- $\mathrm{O}_{2}$, and Li-S. Energy Environ Sci 2015;8:1905-22. DOI

37. Xu K. Electrolytes and interphases in Li-ion batteries and beyond. Chem Rev 2014;114:11503-618. DOI PubMed

38. Santiago A, Castillo J, Garbayo I, et al. Salt additives for improving cyclability of polymer-based all-solid-state lithium-sulfur batteries. ACS Appl Energy Mater 2021;4:4459-64. DOI

39. Zhang H, Oteo U, Judez X, et al. Designer anion enabling solid-state lithium-sulfur batteries. Joule 2019;3:1689-702. DOI

40. Zhang H, Judez X, Santiago A, et al. Fluorine-free noble salt anion for high-performance all-solid-state lithium-sulfur batteries. $A d v$ Energy Mater 2019;9:1900763. DOI

41. Xu W, Wang J, Ding F, et al. Lithium metal anodes for rechargeable batteries. Energy Environ Sci 2014;7:513-37. DOI

42. Zhang S, Ueno K, Dokko K, Watanabe M. Recent advances in electrolytes for lithium-sulfur batteries. Adv Energy Mater 2015;5:1500117. DOI

43. Eshetu GG, Judez X, Li C, et al. Lithium azide as an electrolyte additive for all-solid-state lithium-sulfur batteries. Angew Chem Int Ed Engl 2017;56:15368-72. DOI PubMed

44. Gao X, Zheng X, Wang J, et al. Incorporating the nanoscale encapsulation concept from liquid electrolytes into solid-state lithiumsulfur batteries. Nano Lett 2020;20:5496-503. DOI PubMed

45. Gracia I, Ben Youcef H, Judez X, et al. S-containing copolymer as cathode material in poly(ethylene oxide)-based all-solid-state Li-S batteries. J Power Sources 2018;390:148-52. DOI

46. Manthiram A, Fu Y, Su YS. Challenges and prospects of lithium-sulfur batteries. Acc Chem Res 2013;46:1125-34. DOI PubMed

47. Evers S, Nazar LF. New approaches for high energy density lithium-sulfur battery cathodes. Acc Chem Res 2013;46:1135-43. DOI PubMed

48. Pan H, Cheng Z, He P, Zhou H. A review of solid-state lithium-sulfur battery: ion transport and polysulfide chemistry. Energy Fuels 2020;34:11942-61. DOI

49. Suzuki K, Kato D, Hara K, et al. Composite sulfur electrode prepared by high-temperature mechanical milling for use in an all-solidstate lithium-sulfur battery with a $\mathrm{Li}_{325} \mathrm{Ge}_{0.25} \mathrm{P}_{075} \mathrm{~S}_{4}$ electrolyte. Electrochimica Acta 2017;258:110-5. DOI

50. Nagao M, Hayashi A, Tatsumisago M. Sulfur-carbon composite electrode for all-solid-state Li/S battery with Li2S-P2S5 solid electrolyte. Electrochimica Acta 2011;56:6055-9. DOI

51. Nagata H, Chikusa Y. A lithium sulfur battery with high power density. J Power Sources 2014;264:206-10. DOI

52. Zhang C, Lin Y, Zhu Y, Zhang Z, Liu J. Improved lithium-ion and electrically conductive sulfur cathode for all-solid-state lithiumsulfur batteries. RSC Adv 2017;7:19231-6. DOI

53. Tamate R, Saruwatari A, Nakanishi A, et al. Excellent dispersibility of single-walled carbon nanotubes in highly concentrated electrolytes and application to gel electrode for Li-S batteries. Electrochem commun 2019;109:106598. DOI

54. Ruan J, Sun H, Song Y, et al. Constructing 1D/2D interwoven carbonous matrix to enable high-efficiency sulfur immobilization in Li-S battery. Energy Mater 2021;1:100018. DOI

55. Zhou C, Bag S, He T, Lv B, Thangadurai V. A $20{ }^{\circ} \mathrm{C}$ operating high capacity solid-state Li-S battery with an engineered carbon support cathode structure. Applied Materials Today 2020;19:100585. DOI

56. Liu R, Wu Z, He P, et al. A self-standing, UV-cured semi-interpenetrating polymer network reinforced composite gel electrolytes for dendrite-suppressing lithium ion batteries. Journal of Materiomics 2019;5:185-94. DOI

57. D'angelo AJ, Panzer MJ. Decoupling the ionic conductivity and elastic modulus of Gel electrolytes: fully zwitterionic copolymer scaffolds in lithium salt/ionic liquid solutions. Adv Energy Mater 2018;8:1801646. DOI

58. Tian X, Yi Y, Yang P, et al. High-charge density polymerized ionic networks boosting high ionic conductivity as quasi-solid electrolytes for high-voltage batteries. ACS Appl Mater Interfaces 2019;11:4001-10. DOI PubMed

59. Guo X, Li S, Chen F, et al. Performance Improvement of PVDF-HFP-based gel polymer electrolyte with the dopant of octavinylpolyhedral oligomeric silsesquioxane. Materials (Basel) 2021;14:2701. DOI PubMed PMC

60. Liu M, Zhou D, He Y, et al. Novel gel polymer electrolyte for high-performance lithium-sulfur batteries. Nano Energy 2016;22:27889. DOI

61. Wang Q, Wen Z, Jin J, et al. A gel-ceramic multi-layer electrolyte for long-life lithium sulfur batteries. Chem Commun (Camb) 2016;52:1637-40. DOI PubMed

62. Baloch M, Vizintin A, Chellappan RK, et al. Application of gel polymer electrolytes based on ionic liquids in lithium-sulfur batteries. J Electrochem Soc 2016;163:A2390-8. DOI

63. Agostini M, Lim DH, Sadd M, et al. Stabilizing the performance of high-capacity sulfur composite electrodes by a New Gel polymer electrolyte configuration. ChemSusChem 2017;10:3490-6. DOI PubMed

64. Gao S, Wang K, Wang R, et al. Poly(vinylidene fluoride)-based hybrid gel polymer electrolytes for additive-free lithium sulfur batteries. J Mater Chem A 2017;5:17889-95. DOI

65. Safa M, Hao Y, Chamaani A, et al. Capacity fading mechanism in lithium-sulfur battery using poly(ionic liquid) gel electrolyte. Electrochimica Acta 2017;258:1284-92. DOI

66. Han D, Liu S, Liu Y, Zhang Z, Li G, Gao X. Lithiophilic gel polymer electrolyte to stabilize the lithium anode for a quasi-solid-state lithium-sulfur battery. J Mater Chem A 2018;6:18627-34. DOI

67. Du H, Li S, Qu H, et al. Stable cycling of lithium-sulfur battery enabled by a reliable gel polymer electrolyte rich in ester groups. 
Journal of Membrane Science 2018;550:399-406. DOI

68. M. Shanthi P, J. Hanumantha P, Albuquerque T, Gattu B, Kumta PN. Novel composite polymer electrolytes of PVdF-HFP derived by electrospinning with enhanced Li-ion conductivities for rechargeable lithium-sulfur batteries. ACS Appl Energy Mater 2018;1:483-94. DOI

69. Huang $\mathrm{H}$, Ding F, Zhong $\mathrm{H}$, et al. Nano- $\mathrm{SiO}_{2}$-embedded poly(propylene carbonate)-based composite gel polymer electrolyte for lithium-sulfur batteries. J Mater Chem A 2018;6:9539-49. DOI

70. Wang X, Hao X, Xia Y, Liang Y, Xia X, Tu J. A polyacrylonitrile (PAN)-based double-layer multifunctional gel polymer electrolyte for lithium-sulfur batteries. Journal of Membrane Science 2019;582:37-47. DOI

71. Xia Y, Liang Y, Xie D, et al. A poly (vinylidene fluoride-hexafluoropropylene) based three-dimensional network gel polymer electrolyte for solid-state lithium-sulfur batteries. Chem Eng J 2019;358:1047-53. DOI

72. Deng N, Liu Y, Wang L, et al. Designing of a Phosphorus, Nitrogen, and Sulfur Three-Flame Retardant Applied in a Gel Poly-mphenyleneisophthalamide nanofiber membrane for advanced safety lithium-sulfur batteries. ACS Appl Mater Interfaces 2019;11:36705-16. DOI PubMed

73. Shen Y, Zeng F, Zhou X, et al. A novel permselective organo-polysulfides/PVDF gel polymer electrolyte enables stable lithium anode for lithium-sulfur batteries. Journal of Energy Chemistry 2020;48:267-76. DOI

74. Ye B, Cai X, Wang D, Saha P, Wang G. A novel poly(vinyl carbonate-co-butyl acrylate) quasi-solid-state electrolyte as a strong catcher for lithium polysulfide in Li-S batteries. Electrochimica Acta 2020;332:135463. DOI

75. Zhou D, Shanmukaraj D, Tkacheva A, Armand M, Wang G. Polymer electrolytes for lithium-based batteries: advances and prospects. Chem 2019;5:2326-52. DOI

76. Ma C, Cui W, Liu X, Ding Y, Wang Y. In situ preparation of gel polymer electrolyte for lithium batteries: progress and perspectives. InfoMat. DOI

77. Cheng $\mathrm{H}$, Zhu J, Jin H, et al. In situ initiator-free gelation of highly concentrated lithium bis(fluorosulfonyl)imide-1,3-dioxolane solid polymer electrolyte for high performance lithium-metal batteries. Materials Today Energy 2021;20:100623. DOI

78. Kim SH, Choi KH, Cho SJ, Choi S, Park S, Lee SY. Printable solid-state lithium-ion batteries: a new route toward shape-conformable power sources with aesthetic versatility for flexible electronics. Nano Lett 2015;15:5168-77. DOI PubMed

79. Wang X, Hao X, Cai D, Zhang S, Xia X, Tu J. An ultraviolet polymerized 3D gel polymer electrolyte based on multi-walled carbon nanotubes doped double polymer matrices for lithium-sulfur batteries. Chem Eng J 2020;382:122714. DOI

80. Hao X, Wenren H, Wang X, Xia X, Tu J. A gel polymer electrolyte based on PVDF-HFP modified double polymer matrices via ultraviolet polymerization for lithium-sulfur batteries. J Colloid Interface Sci 2020;558:145-54. DOI PubMed

81. Zhao X, Wang C, Li Z, Hu X, Abdul Razzaq A, Deng Z. Sulfurized polyacrylonitrile for high-performance lithium sulfur batteries: advances and prospects. J Mater Chem A 2021;9:19282-97. DOI

82. Zhang S. Understanding of sulfurized polyacrylonitrile for superior performance lithium/sulfur battery. Energies 2014;7:4588-600. DOI

83. Liu Y, Yang D, Yan W, et al. Synergy of sulfur/polyacrylonitrile composite and gel polymer electrolyte promises heat-resistant lithium-sulfur batteries. iScience 2019;19:316-25. DOI PubMed PMC

84. Wu ZJ, Wu BR, Ren YH, Mu DB, Zhao X. Superior cycling performance of sulfurized polyacrylonitrile cathode assembled with in situ polymerized gel polymer electrolyte. AMR 2014;1070-1072:553-8. DOI

85. Zhang X, Chen K, Sun Z, et al. Structure-related electrochemical performance of organosulfur compounds for lithium-sulfur batteries. Energy Environ Sci 2020;13:1076-95. DOI

86. Yan W, Yan K, Kuang G, Jin Z. Fluorinated quinone derived organosulfur copolymer cathodes for long-cycling, thermostable and flexible lithium-sulfur batteries. Chem Eng $J$ 2021;424:130316. DOI

87. Cheng X, Yan C, Huang J, et al. The gap between long lifespan Li-S coin and pouch cells: The importance of lithium metal anode protection. Energy Storage Materials 2017;6:18-25. DOI

88. Shi L, Bak S, Shadike Z, et al. Reaction heterogeneity in practical high-energy lithium-sulfur pouch cells. Energy Environ Sci 2020;13:3620-32. DOI

89. Kong L, Jin Q, Huang J, et al. Nonuniform redistribution of sulfur and lithium upon cycling: probing the origin of capacity fading in lithium-sulfur pouch cells. Energy Technol 2019;7:1900111. DOI

90. Chen PY, Yan C, Chen P, et al. Selective permeable lithium-ion channels on lithium metal for practical lithium-sulfur pouch cells. Angew Chem Int Ed Engl 2021;60:18031-6. DOI PubMed

91. Dörfler S, Althues H, Härtel P, Abendroth T, Schumm B, Kaskel S. Challenges and key parameters of lithium-sulfur batteries on pouch cell level. Joule 2020;4:539-54. DOI

92. Zhao M, Li BQ, Zhang XQ, Huang JQ, Zhang Q. A perspective toward practical lithium-sulfur batteries. ACS Cent Sci 2020;6:1095104. DOI PubMed PMC

93. Liu W, Guo R, Zhan B, et al. Artificial solid electrolyte interphase layer for lithium metal anode in high-energy lithium secondary pouch cells. ACS Appl Energy Mater 2018;1:1674-9. DOI

94. Wang W, Yue X, Meng J, et al. Lithium phosphorus oxynitride as an efficient protective layer on lithium metal anodes for advanced lithium-sulfur batteries. Energy Storage Materials 2019;18:414-22. DOI

95. Yang Q, Deng N, Chen J, Cheng B, Kang W. The recent research progress and prospect of gel polymer electrolytes in lithium-sulfur batteries. Chem Eng J 2021;413:127427. DOI

96. Angulakshmi N, Dhanalakshmi RB, Sathya S, Ahn J, Stephan AM. Understanding the electrolytes of lithium-sulfur batteries. Batteries \& Supercaps 2021;4:1064-95. DOI 
97. Qian J, Henderson WA, Xu W, et al. High rate and stable cycling of lithium metal anode. Nat Commun 2015;6:6362. DOI PubMed PMC

98. Shin ES, Kim K, Oh SH, Cho WI. Polysulfide dissolution control: the common ion effect. Chem Commun (Camb) 2013;49:2004-6. DOI PubMed

99. Suo L, Hu YS, Li H, Armand M, Chen L. A new class of Solvent-in-Salt electrolyte for high-energy rechargeable metallic lithium batteries. Nat Commun 2013;4:1481. DOI PubMed

100. Cuisinier M, Cabelguen P, Adams BD, Garsuch A, Balasubramanian M, Nazar LF. Unique behaviour of nonsolvents for polysulphides in lithium-sulphur batteries. Energy Environ Sci 2014;7:2697-705. DOI

101. Lee CW, Pang Q, Ha S, et al. Directing the lithium-sulfur reaction pathway via sparingly solvating electrolytes for high energy density batteries. ACS Cent Sci 2017;3:605-13. DOI PubMed PMC

102. Shyamsunder A, Beichel W, Klose P, et al. Inhibiting polysulfide shuttle in lithium-sulfur batteries through low-ion-pairing salts and a triflamide solvent. Angew Chem Int Ed Engl 2017;56:6192-7. DOI PubMed

103. Nakanishi A, Ueno K, Watanabe D, et al. Sulfolane-based highly concentrated electrolytes of lithium bis(trifluoromethanesulfonyl)amide: ionic transport, Li-ion coordination, and Li-S battery performance. J Phys Chem C 2019;123:14229-38. DOI

104. Liu J, Li S, Marium M, et al. Towards practical cells: combined use of titanium black as a cathode additive and sparingly solvating electrolyte for high-energy-density lithium-sulfur batteries. Sustainable Energy Fuels 2021;5:1821-31. DOI

105. Weller C, Pampel J, Dörfler S, Althues H, Kaskel S. Polysulfide shuttle suppression by electrolytes with low-density for high-energy lithium-sulfur batteries. Energy Technol 2019;7:1900625. DOI

106. Kensy C, Schwotzer F, Dörfler S, Althues H, Kaskel S. Impact of carbon porosity on sulfur conversion in Li-S battery cathodes in a sparingly polysulfide solvating electrolyte. Batteries \& Supercaps 2021;4:823-33. DOI

107. Piwko M, Weller C, Hippauf F, Dörfler S, Althues H, Kaskel S. Symmetric lithium sulfide - sulfur cells: a method to study degradation mechanisms of cathode, separator and electrolyte concepts for lithium-sulfur batteries. J Electrochem Soc 2018;165:A1084-91. DOI

108. Liang J, Sun Q, Zhao Y, et al. Stabilization of all-solid-state Li-S batteries with a polymer-ceramic sandwich electrolyte by atomic layer deposition. J Mater Chem A 2018;6:23712-9. DOI

109. Liu J, Qian T, Wang M, Zhou J, Xu N, Yan C. Use of tween polymer to enhance the compatibility of the Li/electrolyte interface for the high-performance and high-safety quasi-solid-state lithium-sulfur battery. Nano Lett 2018;18:4598-605. DOI PubMed

110. Wan Z, Huang Y, Zeng X, et al. Peach gum as an efficient binder for high-areal-capacity lithium-sulfur batteries. Sustainable Materials and Technologies 2021;30:e0334. DOI

111. Huang Y, Shaibani M, Gamot TD, et al. A saccharide-based binder for efficient polysulfide regulations in Li-S batteries. Nat Commun 2021;12:5375. DOI PubMed PMC

112. Yuan Z, Peng HJ, Hou TZ, et al. Powering lithium-sulfur battery performance by propelling polysulfide redox at sulfiphilic hosts. Nano Lett 2016;16:519-27. DOI PubMed

113. He J, Bhargav A, Manthiram A. High-energy-density, long-life lithium-sulfur batteries with practically necessary parameters enabled by low-cost Fe-Ni nanoalloy catalysts. ACS Nano 2021;15:8583-91. DOI PubMed

114. Du Z, Chen X, Hu W, et al. Cobalt in nitrogen-doped graphene as single-atom catalyst for high-sulfur content lithium-sulfur batteries. J Am Chem Soc 2019;141:3977-85. DOI PubMed 